\title{
Mesoaxial synostotic syndactyly with phalangeal reduction
}

INSERM

\section{Source}

INSERM. (1999). Orphanet: an online rare disease and orphan drug data base. Mesoaxial synostotic syndactyly with phalangeal reduction. ORPHA:157801

Mesoaxial synostotic syndactyly (MSSD) with phalangeal reduction is a novel and distinct form of non-syndromic syndactyly including complete syndactyly of the 3rd and 4th fingers with synostoses of the corresponding metacarpals and associated single phalanges, syndactyly of the 2 nd and 3rd toes and 5th fing er clinodactyly. 